\title{
Effect of Graphite Addition on the Mechanical Properties and Microstructure in an Aluminum Composite Produced by High-Energy Ball Milling
}

\author{
J.M. Mendoza-Duarte, R. Martínez-Sánchez, C. Carreño-Gallardo, I. Estrada-Guel
}

Centro de Investigación en Materiales Avanzados (CIMAV). Laboratorio Nacional de Nanotecnología, Miguel de Cervantes No. 120, 31109, Chihuahua, Mexico

Aluminum (Al) exhibits a modest structural performance, but its low density makes the Al very attractive for a diversity of industrial applications. Some methods have been proposed in order to upgrade its mechanical properties. One of them is the addition of fine and insoluble particles in order to form multiphase dispersions called composites. Mechanical milling (MM) is a method frequently used to obtain homogeneous dispersions of reinforcing phases. The reinforcement function is to obstruct the dislocations movement, resulting in an increase of material hardness. These materials produce different levels of hardening, due to differences between elastic interactions with material dislocations [1]. Graphite (Gr) is a component widely used as reinforcement, because is cheap, abundant and can be easily reduced in their particle size. Additionally it forms aluminum carbide, when the composite is sintered [3], this hard phase can complicate the dislocations movement.

This work deals with the synthesis of Al-Gr composites prepared by high-energy ball milling and the evaluation of milling intensity over structure and mechanical response of composites. Pure aluminum powder and natural graphite flakes were used as raw materials. As a first step, graphite was "activated" by processing in a high-energy SPEX $8000 \mathrm{M}$ mill using a hardened vial with steel balls keeping a ball to sample ratio of 5:1. Milling intensities were $0,1,2,4$ and $8 \mathrm{~h}$. The composite preparation was done from mixtures of milled $\mathrm{Gr}$ with $\mathrm{Al}$ powder ( $1 \% \mathrm{Gr}$ in wt.) for $1 \mathrm{~h}$. For mechanical characterization, the milled powders were cold compacted with a circular die under $900 \mathrm{MPa}$ (green samples) and sintered (4h/623 $\mathrm{K})$. The mechanical tests were carried out with an Instron 4468 universal machine. Morphology, size and particle distribution were studied using a SEM model JSM-7201F and a TEM model JEM2200-FS. Thinner $(<100 \mathrm{~nm})$ samples were prepared using a JEM9320-FIB device.

In milled samples, the metal matrix was plastically deformed due to impact forces by the collision of milling media and exhibits a change in shape from spheroidal (Fig. 1a) to flake-like (Fig. 1b-c), because of the aluminum ductility. Macroscopically, the density (Fig. 2) can indicate the compaction level and gas presence, which affect the mechanical performance of samples. High density found in un-milled samples is characteristic of spherical morphology and broad particle sizes, where powders pack densely. On the other hand, milled samples exhibit an important density reduction because the presence of large particles that induces a deficient powder packing. In that way, density variation results from changes in particle morphology, which is consequence of pre-milling process of graphite.

The curves of compressive tests for the prepared composites are reported in Fig. 2b. The milled $\mathrm{Al}_{\text {pure }}$ sample presents better mechanical performance compared with unmilled sample, due to cold worked and high internal stress caused by the increment of dislocation density and grain size reduction achieved during milling. However, the highest mechanical response was reached with the $\mathrm{AlGr}(8 \mathrm{~h})$ composite. But this sample presents a reduction of the elongation rate, caused by low densification and high porosity level. 
[1] S. Goussous, W. Xu, X. Wu, K. Xia, Compos. Sci. Technol. 69 (2009) 1997-2001.

[2] H. Kwon, M. Estili, K. Takagi, T. Miyazaki, A. Kawasaki. Carbon 47 (2009) 570-577.

[3] The Research was supported by CONACYT (Project No. 169262) and Redes Temáticas de

Nanociencias y Nanotecnología (124886).
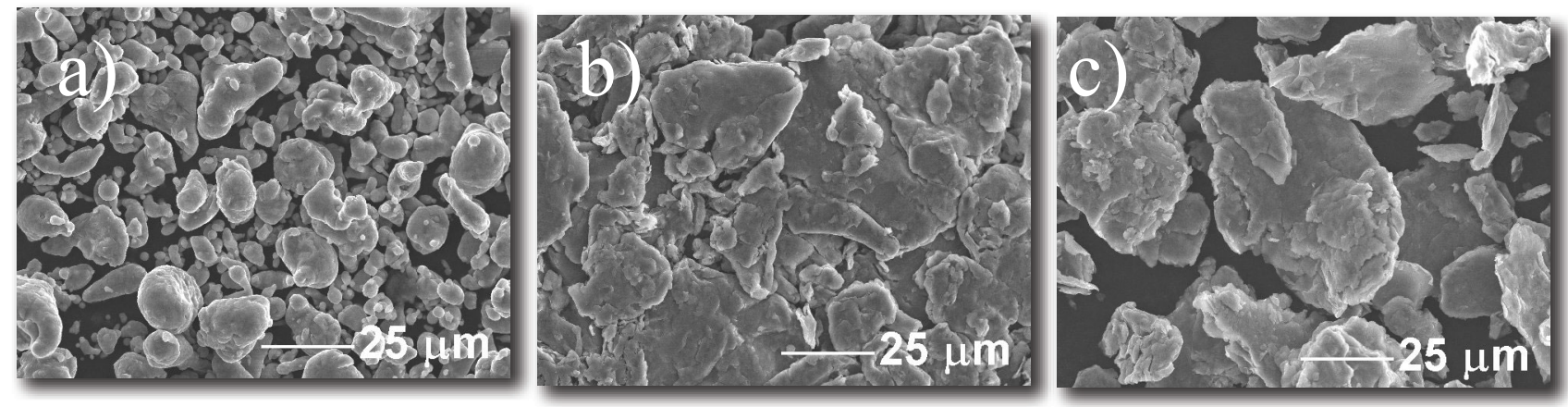

Figure 1. SEM micrograph of composites showing the "activation" effect of graphite over the morphology and particle size of some Al-Gr composites milled for $1 \mathrm{~h}$. a) $\mathrm{Al}_{\text {unmilled }}$ b) $\mathrm{Al}-\mathrm{Gr}(0)$ and c) $\mathrm{Al}-\mathrm{Gr}(4)$.
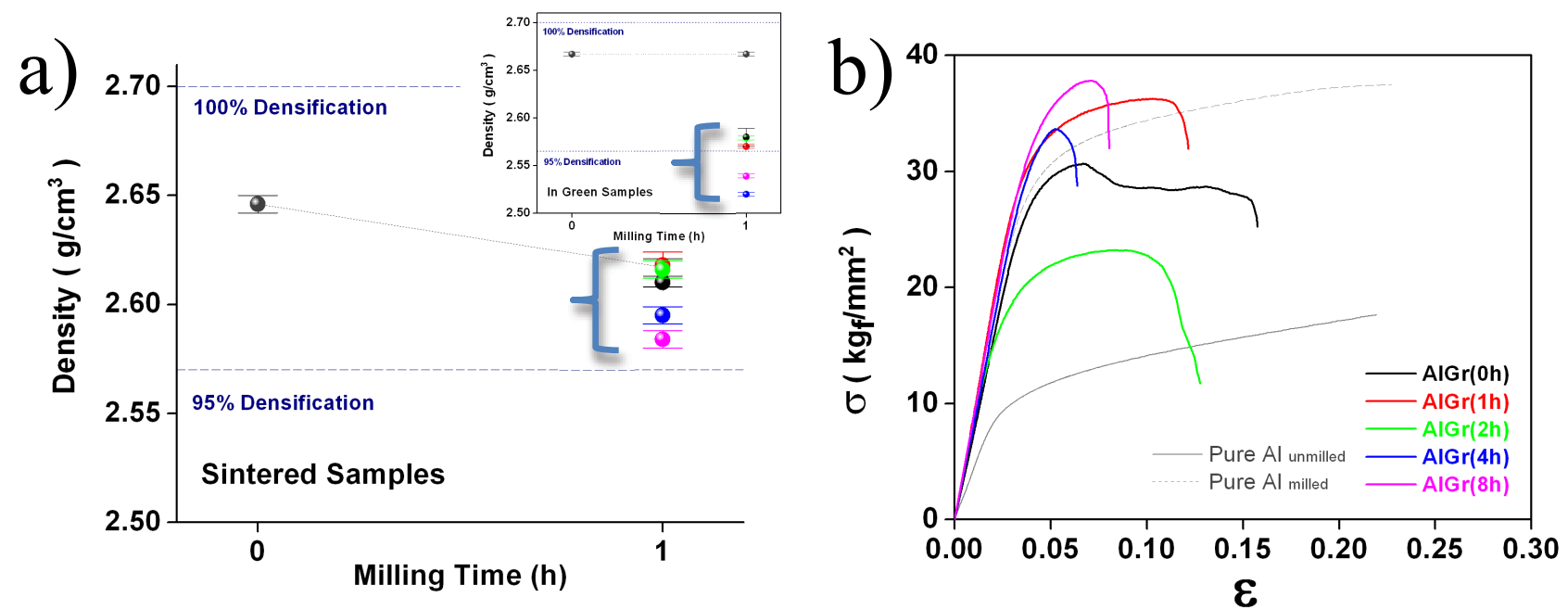

Figure 2. a) Density determination of compacted composites, after sintering all samples present densification values above of $95 \%$. b) Strain-stress curves prepared composites (compressive tests), composites presents a fall in ductility, this is possibly caused by the high stress concentration produced by presence of hard phases in the Al matrix.
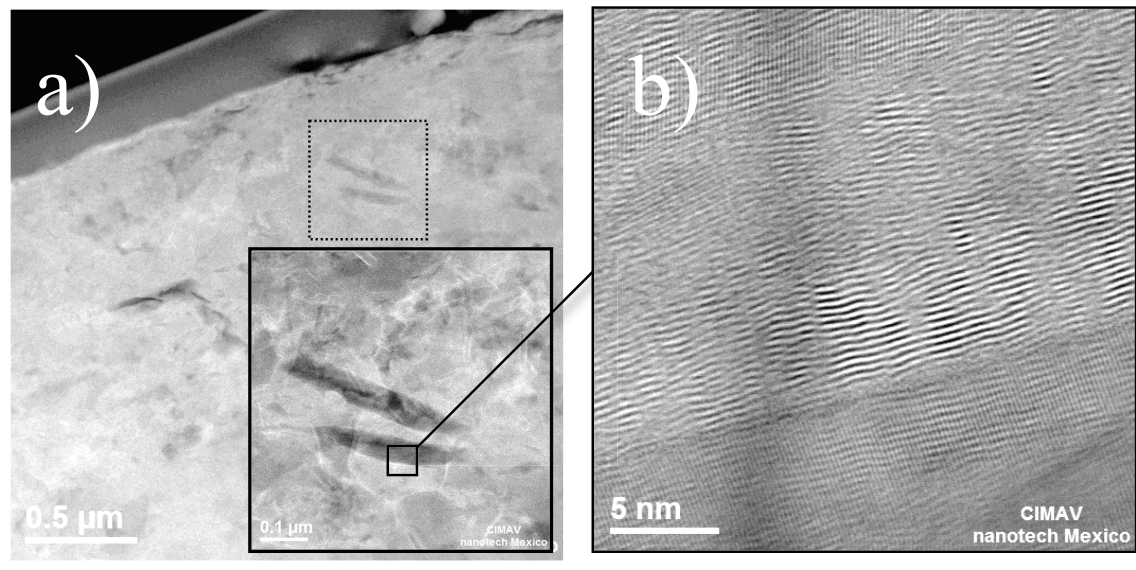

Figure 3. a) STEM micrograph of $\operatorname{AlGr}(8 \mathrm{~h})$ sample, note the presence of nanometric $\mathrm{Gr}$ particles in the Al matrix. b) HRSTEM image showing a high distortion in the Gr structure (top) as a direct consequence of milling process. 